\title{
Family Literacy Programs as Intersubjective Spaces: Insights from Three Decades of Working in Culturally, Linguistically and Socially Diverse Communities
}

\author{
JIM ANDERSON \\ University of British Columbia \\ ANN ANDERSON \\ University of British Columbia
}

ALISON GEAR
Early Learning Coordinator, School District No. 50 Haida Gwaii

Abstract

In this article we draw on our three decades of work in culturally, linguistically, and socially diverse communities - an economically depressed, rural community in Eastern Canada, a culturally and linguistically diverse metropolitan area of western Canada and a First Nations community in north-western Canada - to document the development and evolution of a social-contextually responsive family literacy program. We propose that family literacy programs can build on the strengths that families bring and provide an intersubjective space where families and schools can share knowledge in a reciprocal, respectful manner.

Over the last three decades or so, researchers have documented that families can play important roles in children's early literacy development (Mui \& Anderson, 2008; Purcell-Gates, 1996; Taylor \& Dorsey-Gaines, 1988). Indeed, Goodman (1980) called the informal, often serendipitous literacy activities and events that occur in homes and communities the roots of literacy. Attempting to capitalize on this knowledge, educators have developed family literacy programs that aim to support families in increasing opportunities for young children to engage in literacy activities and events at home, to enhance their early language and literacy development. Converging evidence indicates that: these programs can have a positive effect on children's language and literacy development (Anderson, Friedrich , \& Kim, 2011; Brooks, Pahl, Pollard, \& Rees, 2008) that is sustained into the elementary school years (St. Clair, Jackson, \& Zweiback, 2012); parents value them (Anderson, Anderson, \& Teichert, 2013); and they can also help teachers and schools understand the lived experiences of culturally and linguistically diverse families and families living in challenging social situations (Anderson, Smythe, \& Shapiro, 2005).

However, there has been considerable criticism of family literacy programs (e.g., Auerbach, 1989) and critics of family literacy programs argue that the literacy practices and home languages of families and communities are ignored and that school literacy practices are imposed on families. While acknowledging that indeed some family literacy 
programs perpetuate deficit notions of families and their language and literacy practices (Anderson, Streelasky, \& Anderson, 2007), we argue that this is not necessarily the case. In this article we draw on three decades of work in culturally, linguistically, and socially diverse communities - an economically depressed, rural community in Eastern Canada, a culturally and linguistically diverse metropolitan area of western Canada and a First Nations community in north-western Canada - to demonstrate that family literacy programs can build on the strengths that families bring and reflect the social-contextual realities of their communities. We first provide the framework and background that informs our work and then we describe the three contexts and explain how we collaborated with the families and communities to ensure that their needs were met and their goals were attained. We then discuss the lessons we learned, and conclude with implications of this work.

\section{Framework}

Our work is informed by socio-historical theory (Vygotsky, 1978) and the notion that learning is social, as well as individual. Children learn to use the "cultural tools" including language of their community and culture inter-psychologically as they are guided and supported by parents and significant other people. As they practice using these "tools" and support is gradually withdrawn, children learn to use them intrapsychologically or independently. As Rogoff (2003) points out, "human development is a cultural process" but "[t]o date, the study of human development has been based largely on research and theory coming from middle class communities in Europe and North America" (p.4). In some cultures for example, parents and other caregivers provide less verbal scaffolding (Wood, Bruner, \& Ross, 1976) than is promoted by many educators in western countries. Children learn through other forms of guided participation including legitimate peripheral participation (Lave \& Wenger, 1991) as they observe more experienced and proficient others execute skills and engage in activities important in their homes and communities.

We also draw on the concept of intersubjectivity (Inghilleri, 1999) and one of its central tenets, shared understanding (Husserl, 1981; Duranti, 2010). That is, researchers (e.g., Au \& Kawakami, 1994) have documented that there is sometimes a lack of shared understanding between non-mainstream families and schools. As Anderson and Morrison (2007) indicate, this lack of shared understanding, or incommensurability, is thought to contribute to children from culturally and linguistically diverse homes and children from working class and poor homes not achieving as well in school as their peers from mainstream homes. Consistent with the notion of intersubjectivity is Pahl and Kelley's (2005) conceptualization of family literacy programs as a "third space" where language and literacy practices from homes and school language and literacy practices are acknowledged and valued and where families and teachers learn from each other - in other words as an intersubjective space.

\section{Working with Families and Communities}

Site A: Rural Community in Eastern Canada

The context. In the late 1980s, when our work in family literacy began, Jim, the first author, and Ann the second author, lived in a small rural community of 
approximately 1800 people in Eastern Canada. The community was a part of a larger incorporated town and the Kindergarten to Grade 9 community school played a significant role in its distinct and its strong sense of identity. This school enrolled all of the approximately 300 children in the community until they reached Grade 10, when they attended secondary school in the larger town. The school had strong community support but it also faced many challenges. A significant number of children were reading and writing below grade level, an inordinate number were being placed in special education classes, and many dropped out of junior or senior high school (Norman, 1997). Within this largely working class community, the children's at-home early literacy and language experiences differed from those at school (Heath, 1983). The community lacked preschool and other early childhood programs and services; attempting to lessen some of the challenges the children faced in school, the school principal lobbied the school district to implement "an early intervention program" that would give the children "a head start" (A. Mercer, personal communication, June 2007). Responding to this request, Jim, first author, who was the assistant superintendent of curriculum and instruction for the school district in which the school was located and colleagues, began a collaborative process to establish the "early intervention" project. At that time, there were few models of responsive family literacy programs to draw upon (Auerbach, 1989). However, those developing the program intuitively knew the importance of involving the community from the beginning of such initiatives and so a series of meetings was held with the school's Parent Advisory Committee, Community Health Nurses, social workers, the priest of the Anglican Church that many of the families attended regularly, and so forth.

The program. Drawing from the discussions at these meetings and ongoing conversations with community members, Jim, along with the district's early childhood consultant, some of the primary grade teachers, and the principal worked collaboratively with the community to conceptualize and develop a program. It was clear that the families and community wanted a program that would help prepare children to be "ready for school". The initiative was geared toward four-year-olds and their parents (or significant other). During the sessions, the adult-child pairs circulated among various learning centers and engaged in age-appropriate activities together. The facilitators - the Kindergarten and Grade 1 teachers and the early childhood consultant-modeled adultchild interactions to support and promote children's learning (Vygotsky, 1978). For example, they read storybooks to the children dialogically and in an age-appropriate manner, and they drew children's attention to print and different texts and their functions and purposes (Anderson, Purcell-Gates, Lenters, \& McTavish, 2012). They asked questions that promoted children's use of decontextualized language (Curenton \& Justice, 2004; Snow, 1983) and encouraged cognitive distancing by prompting children to think beyond the immediate context, the here and now (Siegel, 1984). For example, they asked children to connect objects in storybook illustrations or character's experiences to their own lived experiences and to think beyond the immediate context. In addition, the facilitators shared knowledge about teaching and learning practices and strategies with the families. For instance, they discussed how sorting and counting supports early mathematics learning; they provided examples of children's writing development from drawing and scribbling and explained the role of children's invented spelling, both in 
permitting children to represent their thoughts in print before they can spell conventionally and in revealing the child's emerging understanding of symbol-sound relationships. Finally, each family received various learning resources (e.g., high quality children's books, writing and drawing materials) to take home (and keep) after each session. While Jim visited sessions to provide moral support and demonstrate the district's interest in and commitment to the 'early intervention' project, and at times provide logistical support, he was not directly involved in the delivery of the program. Likewise, the second author Ann (a stay-at-home-parent at the time) and her daughter participated in the program, alongside other adult-child pairs from the community but did not play a role in the program's planning or implementation.

Findings and insights. Twenty years after the family literacy program (i.e., the 'early intervention project') had been first established, Anderson et al. (2013) conducted a study to ascertain families' retrospective views of their experiences in the program. Ten of the 20 families from the original cohort were available and willing to participate in semi-structured interviews in which they shared their memories of their participation in the program and their perceptions of how it affected them and their children. Their insights serve to add depth to our portrayal of this early attempt at delivering a community-based "early intervention" program. For instance, families identified integral parts of the program, such as interacting with their children at the learning centers during the parent-child together time, as being very important. They also felt that being able to observe the modeling of adult-child interactions by the facilitators and other parents was crucial and that the modeling, and the participation in ongoing dialogue and discussion, served to make the child-centered, play-based, curriculum and pedagogy in the school setting more transparent. One parent explained, “... and they were ready for school before school started. And they did not even realize because ... of play”. They attributed these design elements to increasing not only their understanding of the expectations for their children when they entered kindergarten, but also the different ways in which they might support their children's learning prior to entry to school and how to continue that support afterwards. For example, "Ah, it helped me to understand what the, education of my child is gonna be looking like from the beginning. And it helped me to understand what is my part gonna be in that education." Likewise, they spoke of establishing relationships with teachers and feeling comfortable in the school and serving various voluntary roles there. Although at that time, relatively little attention was being paid to transitions from home to school, the parents interviewed noted how the framework of the program (i.e., routines and structures) helped their children "know what to expect" and how to respond when they entered Kindergarten, much more so than their older siblings who in some cases "took a full year [to adjust to] Kindergarten" (Anderson et al., 2013, p. 43). Through this retrospective lens, then, this initiative can be seen as a mutually beneficial endeavor, whereby community and school came together to support one another in strengthening home-school relations and children's learning prior to kindergarten.

Of course, the findings just reported were from interviews, 20 years after families had participated in the program, but they are confirmatory of what we had garnered at the time the program was instituted. First, creating a safe space in the kindergarten class 
where parents and children could engage in hands-on, literacy activities was very important to the families. Our intuition to develop the initiative collaboratively with the families, community and school in terms of what "made sense" to them, in retrospect, was crucial and, we speculate, led to the sense of ownership exuded by the interviewees twenty years later. However, we had underestimated the importance the parents placed on school readiness and on the facilitative role that the program played both in helping children transition to school and in enabling families to feel more comfortable in school and in participating more fully there. We next share how we drew upon what we had learned in this community in another context on the other side of the continent.

\section{Site B: Metropolitan area in Western Canada}

The context. A decade after the initiative in the rural community in Eastern Canada, Jim was teaching and doing research in family literacy as a professor at the University of British Columbia. In 1999, he and a colleague were invited by the mayor of Langley to develop a family literacy program as part of a community development initiative she was leading in two inner city neighborhoods (Anderson \& Morrison, 2000). Building on his previous experiences in the rural community in eastern Canada, he and his colleagues held focus groups with parents/caregivers, early childhood educators, and administrators from the two community schools. They then developed modules, fieldtesting them with families beginning in January, 2000. By September 2000, the various modules had been sufficiently developed and then modified based on feedback from the families to implement a full-fledged program called Parents As Literacy Supporters (PALS).

The program. PALS consists of 10 - 12, two-and-a-half hour sessions, addressing topics that families wanted to learn more about, including learning to read and write, early mathematics, and "computers". Open sessions are included in order to address emerging concerns or issues that arise. For example, one year, the families at one site were concerned about the amount of television their children were watching and so a session was designed to address this issue. Sessions are scheduled in consultation with families in each community according to what works best for them; at some sites, this is first thing in the morning, at others in the afternoon after lunch, while at others after school or late afternoon work best. Each session begins with the families and program facilitators sharing a meal after which the children go to the classroom with an early childhood educator where they engage in age appropriate activities while the parents or other adults accompanying the children stay with the facilitator for half an hour. The topic of the day is introduced (e.g., learning to read) and participants are encouraged to share their recollections of learning to read, and their observations of their children's early reading. The facilitator then provides a brief orientation to the various activity centers for that day. The adults then join the children in the classroom where the learning centers with age- appropriate activities reflecting the topic of the day have been arranged. During the next hour or so, the families circulate among the centers, after which the children go to recess. The adults regroup with the facilitator to debrief, discussing the session - which activities worked well and which might need some adjustment, what they observed about their children's learning, what they learned themselves, how they might 
continue with the activities or similar ones at home, and suggestions for improvements. The families are then presented with a children's book, often connected with the topic of the day or other resources such as writing and drawing materials.

As Jim and his colleagues worked with families in the two inner-city communities, word of the initiative spread and interest in it started to grow. In the second year, they introduced the program to two inner-city schools in a neighboring city and subsequently to various communities throughout the province. Although they always attempted to ensure that the program was culturally and socially responsive, they were concerned that families' home languages were not being promoted within the program, although there are compelling cognitive, educational, linguistic, psychological, and social reasons for doing so (e.g., Bialystok, 2011; Cummins, 1981; Snow, Burns, \& Griffin, 1998; Wong-Fillmore, 2000). Thus they were delighted when the opportunity arose to partner with a not-for-profit organization to develop a bilingual version of the program that would also reflect the cultures of the families with whom they would work.

Consistent with the commitment to involving the broader community from the beginning of initiatives such as this, they formed a working group that consisted of the English as a Second Language Coordinators from five school districts that had large numbers of new immigrant and refugee families and who had indicated interest in the project, the early childhood educators who would be co-facilitators at each site, and a cultural worker from each linguistic group - Farsi, Karen, Mandarin, and Punjabi. They also formed an advisory group consisting of representatives from the various linguistic communities, the not-for-profit organization, and a university professor with expertise in second language acquisition and early language and literacy.

Prior to launching the program, they worked with the cultural workers to translate the materials into the four languages, order dual language books, and so forth. They provided a two-day orientation session for the facilitators who were all experienced, welleducated early childhood educators and discussed readings that had been provided them on topics such as bilingual and bi-literacy education, working with families in culturally sensitive ways, and so forth. They had experts in working with culturally and linguistically diverse children and families lead sessions and address questions and issues that arose.

The program, called Parents As Literacy Supporters in Immigrant Communities essentially follows the design or format of $P A L S$. Bilingual sessions in English and the first language (L1) of the families are co-facilitated by an early childhood educator and the cultural worker. As far as possible, texts such as the agenda of the day, instructions for various activities, and books for children to take home are written in English and the home language. In recognition of culturally diverse ways of teaching and learning, the facilitators attempt to ensure the curriculum and pedagogy are culturally responsive, to build on families" "funds of knowledge" (Moll, Amanti, Neff, \& Gonzalez, 1992).

Throughout the initial two years of the implementation of the program, Jim and his colleague met with the working group approximately every two months, addressing any concerns or issues, making necessary adjustments, providing on-going professional development, and attending to pragmatic issues such as developing new materials and ordering books and other resources. As well, they kept the Advisory Group apprised of the project through regular meetings. To document the implementation of PALS in 
Immigrant Communities, a mixed methods research design employing a number of data collection techniques and instruments ${ }^{1}$ was used. Here, we report some of the findings from the focus group sessions and our field notes.

Findings and insights. Consistent with previous research (Wong-Fillmore, 2000), families were very concerned that their children learn English as quickly as possible. However, they also were supportive of maintaining their home languages and during the focus group sessions, identified various reasons for doing so. For example, one parent commented, "It's very important that they learn in their first language so they will be more connected to their first language. We need food for our body. Our children also need their first language for themselves". Others had more pragmatic reasons: "I will encourage my kids to maintain their Chinese for one reason, the fact that more than onequarter of the world population speak that language so it's very important", continuing to explain that being bilingual would be an advantage for children in terms of obtaining employment once they reached adulthood. Some families who were just beginning to learn English commented how the bilingual nature of the program allowed them to participate more fully as they could access the information and knowledge in their L1 while being provided an opportunity in a safe environment to practice English. Indeed, the ESL district coordinators commented in the working group meetings that the program provided a very supportive pedagogical space for the adults, as well as the children.

Despite the very positive response to the emphasis on L1 maintenance on the part of the adult participants, there were some indications that some of the children were already beginning to reject their home languages in favor of English. For example, one mother reported, "My daughter started to go to pre-school, and have friends from English-speaking society, ... [she] preferred to speak English. I asked my daughter, 'Yah, if I speak Mandarin and English, which one do you prefer?' She preferred English". Other parents reported that their children were reluctant (or refusing) to practice writing in their home language.

In addition to promoting the home language of the families, an aim of the program was to recognize and value the different ways that they supported their children's learning. We attempted to move away from an ethno-centric conceptualization of pedagogy and recognize that different cultural groups mediate learning in different ways (Rogoff, 2003); we documented how families enacted their cultural models (Reese \& Gallimore, 2000) of learning and teaching within the program (Anderson \& Morrison, 2011). For example, with some families, the adult silently modelled an activity such as constructing a craft while the child watched attentively and when the craft was completed, the child then attempted to replicate the process that he or she had observed. With other families, the adult sat close by the child, sometimes lightly touching his or her shoulder as she or he completed a task, but without commenting verbally. And in other

\footnotetext{
${ }^{1}$ It is beyond the scope of this paper to discuss each of these; details can be found at http://decoda.ca/wpcontent/files_flutter/1314987684PALSinImmigrantCommunitiesResearchReportFeb2011.pdf
} 
families, the adult guided the child's actions, hand-over-hand, while she printed her name or painted a picture.

Consistent with our commitment to intersubjectivity (Inghilleri, 1999), we also paid attention to cultural models of learning and teaching in the delivery of the program. Some of the families favored direct instruction or visible pedagogy (Gregory, Williams, Baker, \& Street, 2004). For example, in a session titled Riddles, Raps and Rhymes where families shared nursery rhymes and songs in English and in L1, some of them initially remarked that they spent the session, "just singing". They were therefore appreciative when the facilitators made explicit to them the value of these activities in children's learning and how they promote skills such as phonemic awareness, which is seen as important in learning to read and write alphabetic languages. Likewise, the facilitators provided a handout listing the key ideas from each session to another group of families who wanted to ensure that they instantiated them in the activities they and their children engaged in at home.

Some of the original insights gained in the intervention program in the small town in eastern Canada held here, and for example, the importance of involving families and communities in designing programs from the outset was reaffirmed. In addition, our recognition of the need to recognize and honor different cultural models of learning and teaching and of the need to make explicit how different activities and practices support children's learning was heightened. And while we were pleased with the degree to which families supported home language maintenance and participated in practices to encourage it, we were reminded of the hegemonic power of English (Mrak, 2011) when preschoolers began to reject their home languages.

\section{Site C. First Nations Community in Western Canada}

The context. In 2009, Alison, the third author, was compelled to design a literacy program based on the strengths of the Haida culture after facilitating a puppet-making and book reading event, where she watched a two-year-old boy dance and sing the Raven Dance because he wasn't interested in making a puppet or looking at books. If literacy does, in fact, "[touch] us at our core in that part of ourselves that connects with the social world around us" (Ferdman, 1990, p. 181), she thought as she watched the dance, we have a lot to learn about making early literacy education more accessible and relevant for Indigenous people. We document here the process she used to collaborate with Haida knowledge holders, educators, parents, and grandparents to re-design PALS, using a methodology based on the socio-cultural realities of families living on Haida Gwaii in northwestern British Columbia.

Traditional Haida education was based on family relationships as knowledge was passed orally from one generation to the next. Children learned the skills needed for daily living by watching their elders. This way of life was profoundly disrupted by Canada's assimilation policies, in particular, compulsory formal education. Family relationships and connections to the land were severed as children were taken to residential schools away from their communities. The legacy of the break from traditional education and parenting - and, we argue, lingering discomfort with the current school system - has extended to include the children, grandchildren, and now great-grandchildren of former students (Kershaw \& Harkey, 2011). Juxtaposed with the continued distance between 
many parents and the school system is a relatively recent resurgence of Haida culture, through art, dance, ceremony, and language. In varying degrees, both the pain of a broken heritage as reflected in persisting social and economic challenges and the pride of a cultural renaissance depict this current context.

The discrepancy in academic achievement between Aboriginal and nonAboriginal students in Canada has been thoroughly documented (Brant-Castellano, Davis, \& Lahache, 2000; Cappon, 2008). In 2004, the Haida school district introduced $P A L S$ as a strategy to foster relationships between home and school, thereby improving student success. In an effort to be culturally responsive, the district respected the importance of family relationships by welcoming extended family members into the program. Sessions were based on traditional stories; used the best Aboriginal children's books; invited community members to teach skills such as cedar weaving, dancing and singing; and introduced early math concepts through familiar manipulative materials such as rocks, shells, and feathers. Alison always found it ironic, however, that the facilitators were using the Haida culture to teach the same curriculum, albeit a necessary one, that was imposed through western schooling. Was this truly intersubjectivity, or was it disguised as such by using tools and examples from one culture to teach the values and principles of another? Because of this lingering concern, Alison welcomed the opportunity to redesign $P A L S$ and to document this collaborative process with the local community.

The program. As depicted in Figure 1, Phase I of redesigning the program involved the traditional (Western) research method of personal interviews, conducted in order to gather the background information needed to then move into Phase II, the use of a Sharing Circle, which reflected an Indigenous research approach.

Alison interviewed 11 members of the Haida community, representing diversity in age, education, and socio economic background to ascertain their views on culturally responsive education and what a Haida version of $P A L S$ might look like. In particular, she was interested in knowing what they wanted children to learn from such a program, a perspective that pervades all of the work described in this article.

The purpose of the second phase of the project was to give participants an opportunity to develop a community-based family literacy program using an Indigenous methodology (e.g., Kovach, 2009). Aligned with both constructivist and critical methodologies, and challenging the hierarchy of knowledge and power, Indigenous research methods are based on a fundamentally different understanding of knowledge than that espoused within the academy (Smith, 1999). In utilizing the Sharing Circle, Alison was guided by Indigenous epistemologies which uphold respectful relationships between things - concepts, people, creation, the cosmos, the spirit world - placing participants at the center (Bishop, 2005; Lavallee, 2009; Wilson, 2008). Knowledge is created, therefore, through the collective understanding of the participants as they relate to each other, their experiences, and their ideas. In this form of research, the collaborative process is as important as the research results (Absolon \& Willet, 2005).

The Sharing Circle included Alison and five Haida parents/grandparents, including three educators and a knowledge holder. Aware of the power imbalance inherent in her being a non-Indigenous educator working with a group of Indigenous 
people, Alison shared with the group Bishop's (2005) "five issues of power." Originally proposed by Smith (1999), this series of questions (focusing on initiation, representation, legitimation, accountability, and benefits) places the ownership, control and outcome of research with the participants.

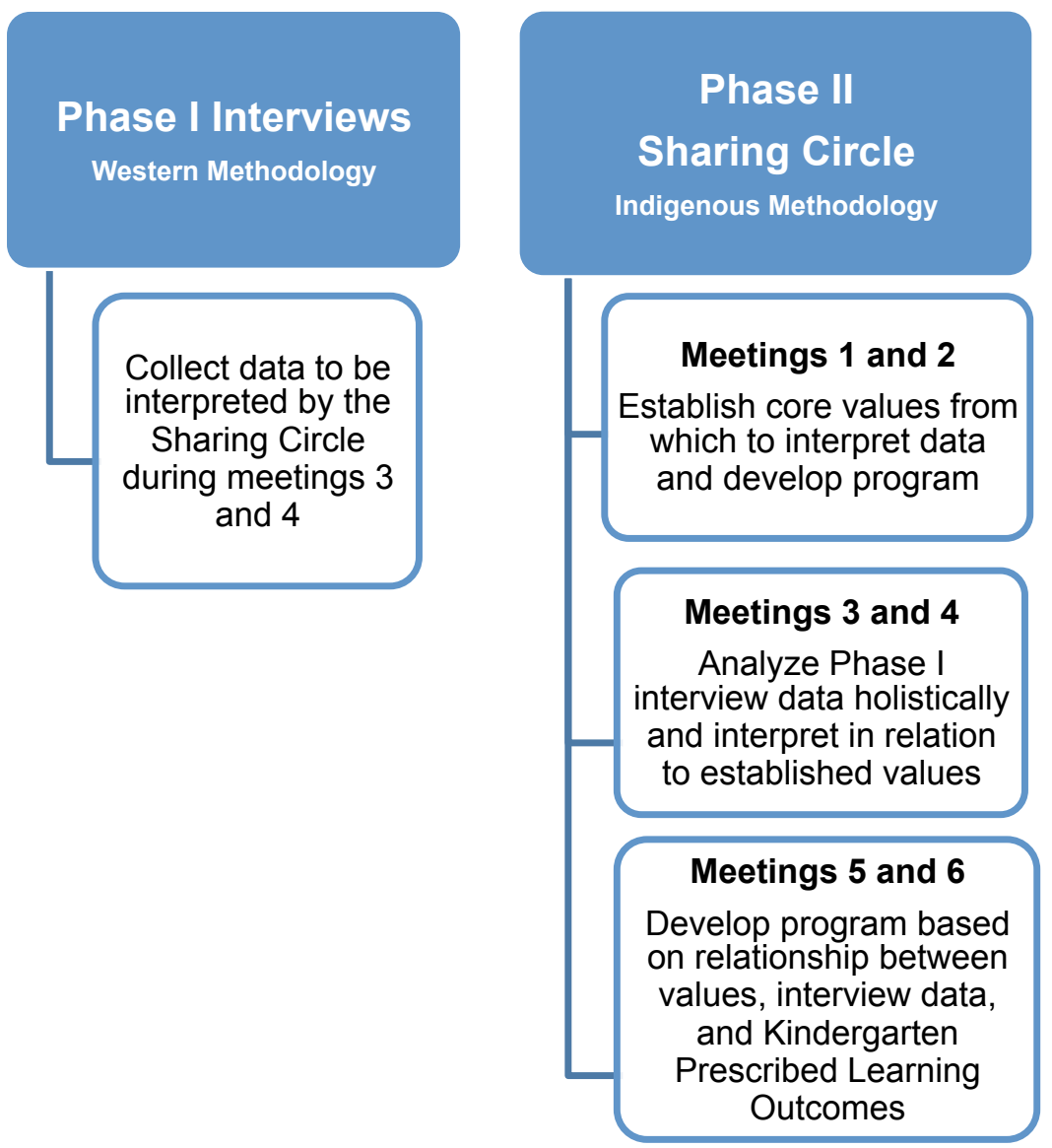

Figure 1. The process.

In facilitating the Sharing Circle, she was inspired by Bishop's (2005) "collaborative storying" process which positions participants at the center and allows them to co-construct meaning reflexively. Following Lavallee's (2009) effective use of symbol creation as a research method, she designed a process whereby participants could create a symbol (made from objects that had been mentioned in the interviews such as cedar, shells, buttons, and pieces of red and black felt) to represent the Haida values and principles they believed should form the core of their circle, representing both how they would work together and what they would create. The first two meetings involved the creation and sharing of these symbols, which were placed in the center of the meeting table, where they remained, on a circular red felt blanket, for the duration of the project. Each subsequent meeting began by looking back at these symbols to ensure that they remained at the core of work, embodying both epistemology and methodology. 
The third and fourth meetings focused on analyzing the interview data. Preceding the discussion on the interviews, Alison introduced the Indigenous model of interpreting data holistically, rather than breaking it down into themes, and thereby "destroying the relationships around it" (Wilson, 2008, p. 119). In order to illustrate this process, she gave each person a differently colored pad of small sticky notes, suggested they all write down the principal ideas, suggestions, or values they had interpreted from the interviews and connect them to the symbols in the middle of the table.

The last two Sharing Circles involved the development of the newly redeveloped Haida Gwaii PALS program. She introduced this aspect of the work by asking participants to consider their understanding of literacy in relationship to the values they had identified. They talked about the Haida principle of balance, and how all their work to that point could be balanced with the Western knowledge embedded in the prescribed learning outcomes of the provincial Kindergarten Curriculum (Jones, 2012). To demonstrate this relationship, Alison placed the Kindergarten Curriculum Package next to the symbols/sticky notes in the center of the table. Through the final phases of their work, they worked to reflect this balance in all aspects of the program.

Haida Gwaii PALS comprises six sessions, each based on a child's connection to one aspect of Haida culture. Sessions follow the standard PALS format of an adult orientation, parent-child activities related to the theme such as learning about the traditional use of the forest on a guided walk, cooking a traditional meal, or writing a story together, and a final reflection time.

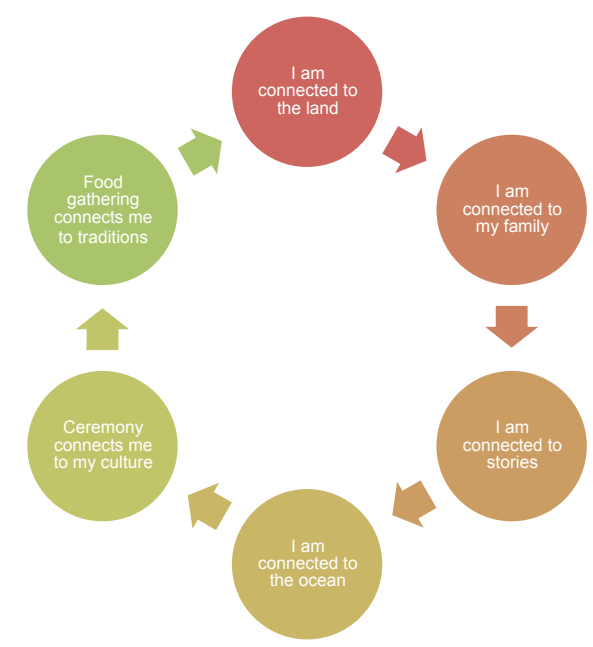

Figure 2. Haida Gwaii PALS sessions.

The program is founded on five objectives which give participants an opportunity to: (a) know more about who they are and where they come from; (b) recognize the equal importance of both Indigenous and Western Knowledge; (c) understand and speak more of the Haida language; (d) feel a sense of home and community in the school and a sense of learning in the home and community; (e) recognize that parents and other family members are their children's most important teachers. 
Findings and insights. The new Haida Gwaii PALS program reflects a circle of knowledge creation. Knowledge, one's understanding of the world, is the foundation of culture. Culture is an expression of that knowledge. Literacy, naturally multimodal in the Haida context, involves the many ways through which the values, beliefs, and norms of the culture are expressed. Learning takes place as people build on these cultural practices and traditions "[changing] their ways of understanding, perceiving, noticing, thinking, remembering, classifying, reflecting, problem setting, planning" (Rogoff, 2003, p. 237). As newly-constructed knowledge is placed in the context of the familiar, as BrantCastellano (2000) illustrates, knowledge, culture, literacy, and learning are continually transformed by each successive generation (Rogoff, 2003).

When parents and children participate in Haida Gwaii PALS activities, they are, in fact, drawing on both Western and Indigenous knowledge systems. A fitting concept for what this program espouses is "syncretic literacy," which describes what happens when children belong to different groups simultaneously - in this case, the Haida culture of their home and community, and the Western culture of the kindergarten classroom and syncretize the literacies, languages, and learning from those two groups to create new ones (Gregory, Long, \& Volk, 2004). In a syncretic relationship, different cultural practices are not mutually exclusive. When home and community cultures are brought into the classroom (and, we argue, when the classroom is brought to the community), children have more opportunities to syncretize the known with the unknown, making their learning more meaningful. According to Knudsen (2004), this understanding of knowledge illustrates how "culture is seen to carry, intrinsically, the seeds of its own continuing renewal" (p. 5). The more that home, community and school literacies are balanced in the classroom, the more opportunities children will have to interpret and shape the world around them. Thus, strengthening the means through which that world can be experienced is seen as the foundation of literacy education.

In keeping with an Indigenous perspective, Haida Gwaii PALS is owned by the people of Haida Gwaii and it is currently being implemented there. Feedback from the first year of the program has been positive. The inclusion of the Haida language and the use of outdoor teaching spaces, such as the forest and beach, were particularly salient in grounding the program in traditional knowledge. Parents have commented that the program "connects students and parents to the land they live on," and that "one PALS day per week should be mandated" in the curriculum. One parent expressed that Haida Gwaii PALS, "is the best way for a young mind to be introduced to learning." The fact that no distinction was made as to whether that learning referred to identifying letters of the alphabet or making a Haida drum illustrates that the learning was, in fact, truly intersubjective. We anticipate that the program will continue to evolve as the community's involvement continues.

\section{Discussion}

In this article, we have documented the evolution of a family literacy program over three decades in communities that are culturally, linguistically and socially diverse. Before discussing our findings, it is important to acknowledge limitations of the studies reported in this article. First, the authors were involved in developing and/or implementing the various stages or iterations of the program. Although we used member 
checks and triangulated various data sources (e.g., field notes, focus group sessions, interviews), and other people, in addition to the authors, were involved in data collection, analysis and interpretation in the various phases, it is important to acknowledge this issue. In future, studies that did not include program developers and facilitators in data collection and analysis would address this issue. As well, although our findings point to the successful development and evolution of a socially contextual responsive family literacy program and although we have received positive anecdotal reports and feedback from parents and teachers, we have not documented its long term impact. Therefore, longitudinal studies that would follow children as they progress through school are called for.

Although many family literacy programs claim to reflect the social-contextual realities of the families and communities they are intended to serve (e.g., Auerbach, 1995), there has been very little documentation in the literature as to how this is the case. In this article, we have described how the program, initially created in the rural community in Eastern Canada reflected a school readiness paradigm as defined by the community, evolved to build on the cultural and linguistic "funds of knowledge" (Moll et al., 1992) of immigrant and refugee families in a large, multicultural metropolitan area, and was transformed to reflect the culture and the epistemologies of a First Nations community utilizing an Indigenous research framework to inform the process.

There is often a clear delineation in the literature between "school literacy" with its emphasis on print and "out-of-school literacy," which is often more broadly conceived as entailing various modes of meaning making and representation. Several points about the work reported in this article need elaboration. Although the initial iteration of the family literacy project reflected a school literacy orientation, it also reflected a multimodal understanding of literacy. For example, we encouraged learning through play, provided opportunity and resources for children to draw and paint, and of course provided the families with picture books, an age-old multimodal resource. On the other hand, while we attempted to capitalize on the families' funds of knowledge and different worldviews and culture in the other two contexts, at the behest of the families and communities, we also paid considerable attention to school literacy and its focus on print. Indeed, based on over three decades of work in the family literacy field, we posit that the dichotomy between school literacy and out-of-school literacy that is evident in the literature appears not to be of concern to the families with whom we have worked, as they seem to be able to see the value of both when they are provided with opportunities in an affirming, supportive context to observe and discuss children's learning.

Related to the previous point, we believe that our work demonstrates the possibilities that family literacy programs can hold as intersubjective spaces. That is, just as families expand their understanding of literacy, learning and teaching, program facilitators also learn about families and communities. For example, we have become much more cognizant of parents' concerns with school readiness, and although the activities we encourage reflect best practices in early childhood education, we ensure that parents are able to see how they indeed are preparing their children for school. And as noted earlier, teachers develop greater understanding of families when they work with them, as they did in the cases described here. Like Cairney and Muncie (1992), we 
believe that reciprocity will occur when family literacy programs are built on genuine respect for families and communities.

As would be expected, over the years we have also faced challenges. Similar to many family literacy programs, sustainability is an issue and for example, PALS in Immigrant Communities depends on short term project grants to run each year, despite the interest in its continuance and expansion. Fidelity to the fundamental principles and understandings of the program is also an ongoing concern. For example, we have noticed the tendency to truncate the debriefing components of sessions where parents have an opportunity to discuss what they have observed, what they have learned, problems they have encountered, and so forth and we have constantly had to work with facilitators in ensuring that this reflective time is maintained. Likewise, although we consistently promoted the importance of using the families' first language in print, such as having the cultural workers present the agenda of each session in L1 and in English, we noted a gradual trend toward using only English, and again, we needed to constantly return to this issue in our meetings and professional development sessions with facilitators. We see these challenges and issues as indicative of the need for the provision of ongoing support, opportunity for reflection, and professional development for facilitators in family literacy programs.

\section{Conclusion}

The three decades of working with families and communities that we presented in this article demonstrate the viability of a social contextual orientation to family literacy programs. We also believe that it points to the need for family literacy providers to be flexible, to listen, and to trust that families and communities understand their needs. Of course, the examples that we presented were of families of very young children and whether the syncretic blending of home and school literacies and different epistemologies that we described here are sustainable as children progress through school is largely unknown.

\section{Acknowledgements}

We would like to thank sincerely the families for their participation in the projects and their generosity in agreeing to participate in the research studies. Appreciation is also extended to the program facilitators and others who participated in and supported the projects including school and district administrators and support personnel, research assistants, government departments, 2010 LegaciesNow, and others who contributed in various ways.

\section{References}

Absolon, K., \& Willet, C. (2005). Putting ourselves forward: Location in Aboriginal research. In L. Brown \& S. Strega (Eds.), Research as resistance: Critical, Indigenous, and anti-oppressive approaches (pp. 97-126). Toronto, ON: Canadian Scholars' Press. 
Anderson, A., Anderson, J., \& Teichert, L. (2013). Through a rear-view mirror: Families look back at a family literacy program. School Community Journal, 23(2), 33-53.

Anderson, J., Friedrich, N., \& Kim, J. (2011). Implementing a bilingual family literacy program with immigrant and refugee families: The case of parents as literacy supporters (PALS). Vancouver, BC: Decoda Literacy Solutions. Available at: http://decoda.ca/wpcontent/files_flutter/1314987684PALSinImmigrantCommunitiesResearchReportFeb2011.pdf

Anderson, J., \& Morrison, F. (2000). The PALS Handbook: Creating and sustaining a Culturally Responsive Family Literacy Program. Langley, BC: British Columbia Langley School District.

Anderson, J., \& Morrison, F. (2007). "A great program... for me as a Gramma": Caregivers evaluate a family literacy initiative. Canadian Journal of Education, $30,68-89$.

Anderson, J., \& Morrison, F. (2011). Learning from/with immigrant and refugee families in a family literacy program. In A. Lazar \& P. Schmidt (Eds.) Practicing what we teach: How culturally responsive literacy classrooms make a difference (pp. 30-38). New York: Teachers College Press.

Anderson, J., Purcell-Gates, V., Lenters, K., \& McTavish, M. (2012). Real-world literacy activity in pre-school. Community Literacy Journal, 8(2), 75-95.

Anderson, J., Smythe, S., \& Shapiro, J. (2005). Working with families, communities and schools: A critical case study. In J. Anderson, M. Kendrick, T. Rogers \& S. Smythe (Eds.), Portraits of literacy across families, communities and schools: Intersections and tensions. Mahwah, NJ: Erlbaum.

Anderson, J., Streelasky, J., \& Anderson, T. (2007). Representing and promoting family literacy on the WWW: A critical analysis. Alberta Journal of Educational Research, 53, 143-156.

Au, K., \& Kawakami, A.J. (1994). Cultural congruence in instruction. In E.R. Hollins, J. E. King, \& W. Hayman (Eds.), Teaching diverse populations: Formulating a knowledge base (pp. 5-23). Albany, NY: State University of New York Press.

Auerbach, E. (1989). Toward a social-contextual approach to family literacy. Harvard Educational Review, 59, 165-81.

Auerbach, E. (1995). Deconstructing the discourse of strength in family literacy. Journal of Reading Behavior, 27(4), 643-661.

Bialystok, E. (2011). Reshaping the mind: The benefits of bilingualism. Canadian Journal of Experimental Psychology, 65(4), 229-235.

Bishop, R. (2005). Freeing ourselves from neocolonial domination in research: A Kaupapa Maori approach to creating knowledge. In N. Denzin \& Y. Lincoln (Eds.), The Sage handbook of qualitative research (3rd ed., pp. 109-138). Thousand Oaks, CA: Sage.

Brant-Castellano, M. (2000). Updating Aboriginal traditions of knowledge. In G.S. Dei, B. Hall, \& D. Rosenberg (Eds.), Indigenous knowledges in global contexts: 
Multiple readings of our world (pp. 21-36). Toronto, ON: University of Toronto Press.

Brant-Castellano, M., Davis, L., and Lahache, L. (2000). Introduction. In M. BrantCastellano, L. Davis, \& L. Lahache (Eds.), Aboriginal Education: Fulfilling the promise. (pp. xi-Xviii). Vancouver, BC: UBC Press.

Brooks, G., Pahl, K., Pollard, A., \& Rees, F. (2008). Effective and inclusive practices in family literacy, language and numeracy: A Review of programmes and practice in the UK and internationally. Reading, UK: CfBT Education Trust.

Cairney, T., \& Muncie, L. (1992). Beyond tokenism: Parents as partners in literacy. Carlton, Australia: Reading Association of Australia.

Cappon, P. (2008, May). Measuring success in First Nations, Inuit and Metis learning. Policy Options, 60-66.

Cummins, J. (1981). Empirical and theoretical underpinnings of bilingual education. Journal of Education, 163(1), 16-29.

Curenton, S., \& Justice, L. (2004). African American and Caucasian preschoolers' use of decontextualized language: Literate language features in oral language. Language, Speech, and Hearing Services in Schools, 35(3), 240-253.

Duranti, A. (2010). Husserl, intersubjectivity, and anthropology. Anthropological Theory, $10(1), 1-20$.

Ferdman, B. M. (1990). Literacy and cultural identity. Harvard Educational Review, 60, 181-204.

Goodman, Y. (1980). The roots of literacy. In M. P. Douglas (Ed.), Claremont Reading Conference Forty-Fourth Yearbook (pp. 1-32). Claremont, CA: Claremont Reading Conference.

Gregory, E., Long, S. \& Volk, D. (2004). A sociocultural approach to learning. In E. Gregory, S. Long \& D. Volk (Eds.), Many pathways to literacy (pp. 6-20). London: Routledge.

Gregory, E., Williams, A., Baker, D., \& Street, B. (2004). Introducing literacy to four year olds: Creating cultures in three schools. Journal of Early Childhood Literacy, 4, 85-107.

Heath, S. B. (1983). What no bedtime story means: Narrative skills at home and at school. Language in Society, 11(1), 49-76.

Husserl, E. (1981). Phenomenology and anthropology. In P. McCormick \& E. A. Elliston (Eds.), Husserl: Shorter works. Notre Dame, IN: University of Notre Dame.

Inghilleri, M. (1999). Intersubjectivity: The holy grail of mutual understanding. Language and Communication, 20, 133-148.

Jones, R. (2012). Oral Presentation by Mr. Russ Jones. Proceedings of the Joint Review Panel for the Enbridge Northern Gateway Project: Hearing Order OH-4-2011, Old Massett, Haida Gwaii, February 28, 2012 (pp. 96-112). Ottawa: International Reporting.

Kershaw, P., \& Harkey, T. (2011). The politics and power in caregiving for identity: Insights for Indian residential school trust and reconciliation. Social Politics, 18, 572-597. doi:10.1093/sp/jxr015 
Knudsen, E. (2004). The Circle and the Spiral: A study of Australian Aboriginal and New Zealand Maori literature. New York, NY: Editions Rodopi B.V.

Kovach, M. (2009). Indigenous methodologies: Characteristics, conversations, and contexts. Toronto: University of Toronto Press.

Lavallee, L. F. (2009). Practical application of an Indigenous research framework and two qualitative Indigenous research methods: Sharing circles and Anishnaabe symbol-based reflection. International Journal of Qualitative Methods, 8, 21-40.

Lave, J., \& Wenger, E. (1991). Situated learning: Legitimate peripheral participation. Cambridge, UK: Cambridge University Press.

Moll, L., Amanti, C., Neff, D., \& Gonzalez, N. (1992). Funds of knowledge for teaching: Using a qualitative approach to connect homes and classrooms. Theory Into Practice, 31(2), 132-141.

Mrak, N. A. (2011). Heritage speakers and the standard: Fighting linguistic hegemony. In L. Ortiz-Lopez (Ed.), Selected proceedings of the $13^{\text {th }}$ Hispanic linguistic symposium (pp. 161-168). Somerville, MA: Cascadilla Proceedings Project.

Mui, S., \& Anderson, J. (2008). At home with the Johars: Another look at family literacy. The Reading Teacher, 62, 234-243.

Norman, P. (1997). The hand that rocks the cradle: An evaluation of the preschool early intervention at St. Mark's School. (Unpublished master's thesis). Memorial University of Newfoundland, St. John's, NL.

Pahl, K., \& Kelly, S. (2005). Family literacy as a third space between home and school: Some case studies. Literacy, 39, 91-6.

Purcell-Gates, V. (1996). Stories, coupons, and the "TV Guide": Relationship between home literacy experiences and emergent literacy knowledge. Reading Research Quarterly, 31, 406-428.

Reese, L., \& Gallimore, R. (2000). Immigrant Latinos' cultural models of literacy development: An evolving perspective on home-school discontinuities. American Journal of Education, 108(2), 105-134.

Rogoff, B. (2003). The cultural knowledge of human development. Oxford: Oxford University Press.

Siegel, I. (1984). Reflections as action theory and distancing theory. Human Development, 27, 188-193.

Smith, L. T. (1999). Decolonizing methodologies: Research and Indigenous peoples. London: Zed Books.

Snow, C. (1983). Literacy and language: Relationship during the preschool years. Harvard Educational Review, 53(2), 165-189.

Snow, C. E., Burns, M. S., \& Griffin, P. (Eds.). (1998). Preventing reading difficulties in young children. Washington, DC: National Academy Press.

St. Clair, L., Jackson. B., \& Zweiback, R. (2012). Six years later: Effects of family literacy on the language skills of children from migrant families. Community School Journal, 22(1), 9-19.

Taylor, D., \& Dorsey-Gaines, C. (1988). Growing up literate: Learning from inner-city families. Portsmouth, NH: Heinemann.

Vygotsky, L. (1978). Mind in society: The development of higher psychological processes. Cambridge, MA: Harvard University Press. 
Wilson, S. (2008). Research is ceremony. Halifax, NS: Fernwood Publishing.

Wong-Fillmore, L. (2000). Loss of family languages: Should educators be concerned? Theory into Practice, 39(4), 203-210.

Wood, D. J., Bruner, J. S., \& Ross, G. (1976). The role of tutoring in problem solving. Journal of Child Psychiatry and Psychology, 17(2), 89-100.

\section{Author Biographies}

Dr. Jim Anderson is a professor in the Department of Language and Literacy Education at the University of British Columbia. His research and teaching focus on early literacy and family literacy. Prior to joining UBC, he worked in the public education system as a teacher, reading specialist, language arts coordinator, and assistant superintendent of curriculum and instruction. His work in family and community literacy spans three decades. With colleagues, he is currently conducting a Social Sciences and Humanities Research Council of Canada supported study of young children's digital tool use at home and in the community.

Dr. Ann Anderson is a professor in the Department of Curriculum and Pedagogy at the University of British Columbia. Her research interests are in mathematics education in the early years. Her funded research projects have included a longitudinal study of early mathematics learning in home and preschool environments as well as collaborative research with early literacy colleagues, studying the emergence and mediation of multiple literacies in young children from diverse backgrounds. Currently, she and her colleagues are embarking on a study of young children's engagement with digital tools and technology at home and in the community.

Alison Gear is the Early Learning Coordinator for School District No. 50 Haida Gwaii, British Columbia. Her work entails developing culturally responsive curriculum and pedagogy in collaboration with First Nations educators and communities. In 2013, Alison received the Best Masters Paper Award from the Association of Literacy Educators and Researchers, one of the oldest literacy organizations in North America, for her research documenting the development of the Haida PALS program. 